\title{
Introduction to the Special Issue: Discrepancies in Adolescent- Parent Perceptions of the Family and Adolescent Adjustment
}

\author{
Andres De Los Reyes ${ }^{1}$ - Christine McCauley Ohannessian ${ }^{2,3}$
}

Received: 18 June 2016/ Accepted: 22 June 2016/Published online: 6 July 2016

(c) Springer Science+Business Media New York 2016

\begin{abstract}
Researchers commonly rely on adolescents' and parents' reports to assess family functioning (e.g., conflict, parental monitoring, parenting practices, relationship quality). Recent work indicates that these reports may vary as to whether they converge or diverge in estimates of family functioning. Further, patterns of converging or diverging reports may yield important information about adolescent adjustment and family functioning. This work is part of a larger literature seeking to understand and interpret multi-informant assessments of psychological phenomena, namely mental health. In fact, recent innovations in conceptualizing, measuring, and analyzing multi-informant mental health assessments might meaningfully inform efforts to understand multi-informant assessments of family functioning. Therefore, in this Special Issue we address three aims. First, we provide a guiding framework for using and interpreting multi-informant assessments of family functioning, informed by recent theoretical work focused on using and interpreting multi-informant mental health assessments. Second, we report research on adolescents' and parents' reports of family functioning that leverages the latest methods for measuring and analyzing patterns of convergence and divergence between informants' reports. Third, we report research on measurement invariance and its role in interpreting adolescents' and
\end{abstract}

Andres De Los Reyes

adlr@umd.edu

1 Department of Psychology, University of Maryland at College Park, College Park, MD, USA

2 University of Connecticut School of Medicine, Farmington, CT, USA

3 Connecticut Children's Medical Center, Farmington, CT, USA parents' reports of family functioning. Research and theory reported in this Special Issue have important implications for improving our understanding of the links between multi-informant assessments of family functioning and adolescent adjustment.

Keywords Family · Informant discrepancies · Multiple informants · Operations Triad Model · Parenting

\section{Introduction}

Adolescents lead complex lives. Relative to earlier developmental periods, adolescence can be characterized by an expansion in exposure to social contexts that may pose risk for or buffer against the development and maintenance of psychosocial maladjustment (e.g., Paus et al. 2008; Smetana et al. 2006; Steinberg 2005). One social context in which this is most readily apparent is the family. For example, as adolescents progress from the early through mid-to-late adolescent periods, frequencies of conflict interactions with parents remain stable, and yet normatively the intensity of this conflict increases over development (Laursen et al. 1998). Of note, very high, chronic levels of such conflict place adolescents at increased risk for a host of poor psychosocial outcomes (e.g., substance use, delinquency, and risk-taking behavior; Ary et al. 1999; Duncan et al. 1998).

During adolescence, families may display profound variations in domains of family functioning other than adolescent-parent conflict. For instance, a family may display relatively high levels of adolescent-parent conflict, yet the adolescent may frequently disclose their whereabouts to parents, a characteristic that tends to buffer adolescents against the development of poor outcomes (e.g., Smetana 2008). As another example, consider a family that displays 
relatively low levels of adolescent-parent conflict, and at the same time the parent displays both inconsistent parenting practices (e.g., variable rule-setting) and a low degree of knowledge of the adolescents' whereabouts and activities, both of which tend to pose increased risk for adolescents developing poor psychosocial outcomes (e.g., Darling and Steinberg 1993; Racz and McMahon 2011). Stated another way, a family may harbor an environment typified by a collection of characteristics that pose risk for and buffer against the development of poor psychosocial outcomes in an adolescent within that family.

Beyond family-level variations in displays of risk and protective factors for adolescents' psychosocial functioning, displays of family functioning vary in their observability. For example, intense adolescent-parent conflict may occur frequently and in public view. As such, the adolescents and parents involved as well as outside observers (e.g., adolescents' peers and other family members) may have frequent opportunities to observe displays of such conflict, even within short time windows. In contrast, inconsistent parenting practices within a family (e.g., rule-setting sometimes and not other times; presence/absence of weekend curfew) may only be observable by people who have both an intimate perspective on the family's functioning, and a long time window within which to observe displays of inconsistent parenting practices.

Collectively, concerns about both family-level variations in displays of family functioning and the observability of these displays necessitate the use of comprehensive approaches to assessment. The most commonly implemented approach involves taking multiple informants' reports of family functioning domains (see also Hunsley and Mash 2007). Using this approach, researchers gather reports from those involved in family interactions (e.g., parents and adolescents). Multiple informants' reports may also be augmented by data from other sources, such as independent observers' ratings of family interactions (e.g., level of warmth or hostility displayed within a laboratory-based family discussion task; De Los Reyes et al. 2015b), or direct assessments of physiological processes as they manifest within relevant contexts (e.g., elevations in arousal or decreased physiological flexibility displayed during computer-based tasks, unstructured home observations, periods of social stress, or a resting period; Aldao and De Los Reyes 2015; De Los Reyes et al. 2015a; De Los Reyes and Aldao 2015; Cohen et al. 2015; Franklin et al. 2015; Leitzke et al. 2015; McLaughlin et al. 2015; Youngstrom and De Los Reyes 2015). Further, a key focus of this approach involves collecting assessments of psychosocial outcomes commonly linked to family functioning, such as adolescent psychosocial functioning, which may also leverage multi-informant, multi-method measurement approaches (e.g., reports of adolescents' mental health from adolescents, parents, teachers, clinicians, and independent observers).

\section{Ubiquity of Adolescent-Parent Reporting Discrepancies}

The value of multi-informant approaches to assessment lies in the unique views that information sources have about the constructs for which they provide reports (Achenbach et al. 1987). In particular, adolescents and parents may vary in the domains of family functioning about which they have robust capacities to observe (e.g., parents and perceived levels of knowledge about adolescents' whereabouts and activities vs. adolescents and perceived levels of disclosure about their whereabouts and activities; Kraemer et al. 2003). Consequently, adolescents and parents may provide reports that provide incrementally valuable information about family functioning, relative to each other (i.e., each report contributes non-overlapping information that is not contributed by the other report). Yet, researchers often encounter challenges with using and interpreting adolescents' and parents' reports of family functioning, because their reports commonly result in discrepant estimates of family functioning (for a review, see De Los Reyes 2013).

Much of our knowledge about these informant discrepancies comes from research that examines magnitudes and moderators of correspondence (i.e., relations between two or more reports of the same person) among informants' reports of psychosocial functioning. To assess children and adolescents, these informants may include parents, teachers, peers, and the children/adolescents themselves (Hunsley and Mash 2007; Rescorla et al. 2014). For adults, selfreports and clinician ratings may be the most often used sources, although over the last decade, researchers have increasingly leveraged reports from collateral informants, such as significant others of the adults being assessed (e.g., spouses, caregivers in the case of elderly adults; Achenbach 2006). Over 50 years of work across hundreds of investigations of informants' reports of children, adolescents, and adults indicates that mean cross-informant correspondence hovers in the low-to-moderate range (e.g., Pearson r's in the $.20 \mathrm{~s}-.40 \mathrm{~s}$; Achenbach et al. 1987, 2005; De Los Reyes et al. 2015b). However, correspondence does not remain uniform across informants. That is, informants' reports tend to exhibit relatively higher correspondence levels when they (a) come from informants who observe behavior in the same context (e.g., pairs of teachers; pairs of parents), (b) estimate levels of behaviors that are relatively easier to observe (e.g., externalizing behaviors such as aggression/hyperactivity vs. internalizing behaviors such as anxiety/mood), and (c) come from continuous versus discrete scales (De Los Reyes et al. 2013e, 2015b). 
The low-to-moderate correspondence levels among informants' reports seen in mental health assessments generalize to correspondence between adolescents' and parents' reports of family functioning domains. Four important observations about these effects warrant comment. First, as mentioned previously, one observes the largest magnitudes of cross-informant correspondence in reports of mental health from informants who observe behavior within the same context (e.g., reports about a child's behavior from a pair of teachers at the child's school). Interestingly, adolescents and parents often provide reports of family functioning domains that, by definition, occur within the same context of observation (i.e., the family unit). Based on this, one might presume that correspondence between adolescents' and parents' reports of family functioning should resemble the relatively high levels of correspondence between the mental health reports of informants from the same context (i.e., Pearson r's in $.50 \mathrm{~s}$; see Achenbach et al. 1987; De Los Reyes et al. 2015b). Yet, this is often not the case: Correspondence levels between adolescents' and parents' reports of family functioning routinely hover in the low-to-moderate range. Indeed, this pattern manifests in assessments of a host of domains including adolescent-parent conflict (e.g., Gonzales et al. 1996), inter-parental conflict (e.g., Epstein et al. 2004), parenting behaviors (e.g., Guion et al. 2009; Otterpohl and Wild 2015), parental monitoring (e.g., parental knowledge, adolescent disclosure, parental solicitation and control; Kerr and Stattin 2000), and adolescent-parent relationship quality (e.g., Pelton and Forehand 2001).

Second, underlying the low-to-moderate levels of correspondence between adolescents' and parents' reports of family functioning, there exist substantial dyad-level variations in patterns of adolescents' and parents' reports about the family. That is, not all adolescents and parents diverge in their reports about the family. In fact, within samples of adolescent-parent dyads, some provide reports that converge quite highly with each other whereas other dyads do not (e.g., De Los Reyes et al. 2010; Lippold et al. 2013). Further, among those adolescent-parent dyads who evidence divergence between their reports, sometimes it is because the parent views family functioning more favorably than the adolescent, and sometimes the reverse is the case and the adolescent views the family more favorably than the parent (e.g., Lippold et al. 2011, 2014; Yaban et al. 2014).

Third, on the surface, discrepancies between adolescents' and parents' reports about family functioning may have the "look and feel" of other family functioning domains, namely conflict. Indeed, prior work indicates that disagreements arising from daily life occurrences (e.g., doing chores and homework) give rise to conflict between adolescents and parents (e.g., Smetana 1989). One question may be, to what extent are discrepant views between adolescents and parents about the family distinguishable from behavioral conflict? Importantly, adolescents' and parents' discrepant views of the family can be empirically distinguished from their levels of behavioral conflict. For instance, research indicates that Pearson correlations between indices of adolescent-parent discrepant views and adolescent-parent conflict hover in the $.10 \mathrm{~s}-.60 \mathrm{~s}$ range depending on the measurement method and informant (De Los Reyes et al. 2012). Further, whereas indices of adolescent-parent discrepant views uniquely predict scores on performance-based measures of interpersonal perception (i.e., emotion recognition), indices of adolescent-parent conflict do not (De Los Reyes et al. 2013c). Taken together, these findings indicate that adolescent-parent discrepancies and conflict, though related, provide distinct information about family functioning and interpersonal perception.

Fourth, the work reviewed previously indicates that (a) low-to-moderate adolescent-parent correspondence is the norm; (b) dyads vary considerably as to patterns of convergence and divergence between reports; (c) when dyads' reports diverge, the direction of this divergence may vary between dyads (adolescent $>$ parent vs. parent $>$ adolescent); and (d) discrepancies between adolescents' and parents' reports contain information about family functioning that relates to, but is distinct from, other domains of family functioning. In light of this work, it is important to consider the importance of understanding and interpreting points of convergence and divergence between adolescents' and parents' reports of family functioning. To begin, consider that when adolescents and parents provide researchers with reports about family functioning domains (e.g., conflict, parenting, relationship quality), they are providing their impressions of features of their lives that may matter a great deal to them (see also De Los Reyes 2011; De Los Reyes and Kazdin 2006a). Thus, patterns of convergence and divergence between adolescents' and parents' reports of such functioning may reflect important aspects of their interactions and how they relate to one another (De Los Reyes et al. 2013c; Goodman et al. 2010). In line with this view, recent work indicates that both the convergence between adolescents' and parents' reports, as well as the divergence between these reports, longitudinally predicts psychosocial outcomes among adolescents (e.g., De Los Reyes 2011; Laird and De Los Reyes 2013; Lippold et al. 2013; Ohannessian and De Los Reyes 2014). Consequently, understanding patterns of adolescents' and parents' reports of family functioning may result in tools for predicting adolescent adjustment.

\section{Importance of Sound Approaches to Modeling Informant Discrepancies}

Overall, prior work in adolescent development greatly informs our understanding of discrepancies between 
adolescents' and parents' reports of family functioning. Further, work on these informant discrepancies and how they operate in other assessment literatures (e.g., multiinformant assessments of mental health) might augment research in adolescent development, and provide researchers with avenues for hypothesis generation and theoretical development. Yet, three key issues need to be addressed to further improve our understanding of multiinformant assessments of family functioning and their links to adolescent adjustment.

The first involves improving our approaches to measuring informant discrepancies. As in other literatures (e.g., mental health; organizational behavior; neuroscience; De Los Reyes and Kazdin 2004; Edwards 1994; Meyer et al. 2016), researchers examining discrepancies between adolescents' and parents' reports of family functioning often seek to measure the distance or "gaps" between these reports, and test whether variations in these gaps relate to variations in scores from criterion variables (e.g., adolescent psychosocial functioning). Historically, these measurements often consisted of taking the difference between one informant's report of a family functioning domain (e.g., adolescent report of family conflict) from another informant's report on that same domain (e.g., parent report of family conflict). Researchers subsequently treated this difference score as an individual differences variable but more importantly, as a new construct that exists over-andabove the construct(s) reflected in the individual reports of the informants (i.e., discrepancies between adolescents' and parents' views of family conflict vs. adolescents' and parents' unique views of family conflict).

We have learned a great deal about these difference scores and what they are capable of providing in the way of measuring informant discrepancies. In short, they provide very little information. Specifically, work from organizational behavior research finds that difference scores are often incapable of contributing incremental or unique information about psychological constructs (e.g., discrepancy between employee's attributes and fit with an organization), over-andabove the scores used to create them (Edwards 2002). Stated another way, difference scores are statistically redundant with the scores contained in the difference scores. Further, these inherent limitations to difference scores generalize to assessments of informant discrepancies in assessments conducted in clinical research and developmental psychopathology generally (Laird and Weems 2011). In fact, recent work provides a set of analytic tools that one can use to test whether a specific use of difference scores can meaningfully inform prediction of scores from criterion variables, over-and-above its component scores (Laird and De Los Reyes 2013). In many cases, researchers may encounter disappointment with what a difference score can offer in the way of incremental prediction of scores from criterion variables.
The issues raised by difference scores have led researchers to develop new techniques for modeling differences and/or similarities between reports. For instance, researchers may study interactions between informants' reports within a polynomial regression framework to examine discrepant perceptions in dyads. This approach allows for the direct examination of whether differences between reports contribute to predicting scores on criterion variables, beyond the main effects of individual reports (Laird and De Los Reyes 2013). Moreover, polynomial regression methods can be modified for use in examinations of discrepant views as either predictors, outcomes, or both (De Los Reyes et al. 2016b; Laird and LaFleur 2016). Thus, the polynomial regression approach can generalize to examining changes in informant discrepancies over time. Further, the polynomial regression approach has been extended to understanding and interpreting informant discrepancies in other areas, including neuroscience, personality, and treatment (Fjermestad et al. 2016; Meyer et al. 2016; Tackett et al. 2013). Other approaches possess similar capabilities and have been successfully implemented in the study of informant discrepancies. These include metaanalysis of cross-informant correspondence (e.g., Achenbach et al. 1987; De Los Reyes et al. 2015b), direct assessment of discrepant views (i.e., via structured interview: De Los Reyes et al. 2012, 2013d), nested repeated measures analytic models (e.g., generalized estimating equations; Alfano et al. 2015; Augenstein et al. 2016; De Los Reyes et al. 2013b); and person-centered models (e.g., latent class analysis; De Los Reyes et al. 2009, 2011, 2016a, 2013a; Lippold et al. 2011, 2013, 2014). In line with this recent work, a key aim of this Special Issue is to report recent work on discrepancies between adolescents' and parents' reports of family functioning, using these emerging measurement and analytic models.

\section{An Increased Focus on Measurement Invariance}

A second issue related to the first is that of the interpretability of discrepancies between adolescents' and parents' reports of family functioning. Specifically, when interpreting differences between informants' reports, informants ought to provide such reports on identical or parallel measures. Indeed, to do otherwise would present a confound: Informants might provide discrepant reports because the item content or response options differed between the measures they completed (see Schwarz 1999). Thus, methodological differences in measurement might parsimoniously account for the discrepancies between two informants' reports, rather than any meaningful difference in how the two informants perceived the psychological phenomena about which they were tasked to provide reports. Thus, one prerequisite of research on informant 
discrepancies involves use of parallel instruments (De Los Reyes et al. 2013e).

Yet, even when informants do provide reports on parallel measures, their reports might be based on measures for which scores taken from them differ in their psychometric properties. If informants' reports do not come from measures for which their scores carry the same properties, then differences between reports might be parsimoniously explained by measurement error. Consequently, in recent years research on multi-informant assessment has focused on the measurement invariance of parallel forms administered to multiple informants (e.g., Dirks et al. 2014), or whether scores from reports of multiple informants can be meaningfully interpreted as carrying the same or similar psychometric properties. However, only recently have these methods begun to be applied to understanding the measurement invariance of adolescents' and parents' reports of family functioning (e.g., Gross et al. 2016; Janssens et al. 2015). Therefore, a second key aim of our Special Issue involves reporting research on the measurement invariance of adolescents' and parents' reports of family functioning.

\section{Need for Theoretical Modeling to Unify Research Efforts}

A key condition underlying current problems with measurement and analytic modeling of multi-informant data is the lack of a unifying framework to guide research on multi-informant assessments of family functioning. That is, a few theoretical models exist that seek to explain or improve interpretability of informant discrepancies (e.g., De Los Reyes and Kazdin 2005, 2006b; Goodman et al. 2010; Kraemer et al. 2003). However, these models focus on domains other than family functioning, such as mental health, treatment outcome, and youth victimization.

Recent work on theoretical modeling of multi-informant mental health assessments seeks to guide research on interpreting the outcomes of these assessments (De Los Reyes et al. 2013e). With some modification, this framework may improve the study and interpretability of multiinformant assessments of family functioning. Specifically, researchers designed the Operations Triad Model to understand and interpret multi-informant assessments of mental health. In Fig. 1 we present a graphical depiction of the Operations Triad Model. In these assessments, multiple informants provide reports about a target person's mental health (e.g., parent and teacher report about a child's behavior problems). As with assessments of family functioning, these reports may provide unique information about mental health that converge on estimates of such mental health (i.e., Converging Operations; Fig. 1a). This convergence may result in the informants' reports pointing to a common conclusion. Additionally, this convergence might reflect meaningful consistencies in assessed behaviors across contexts. For example, if a parent and teacher both report that a child displays relatively high behavior problems, then this convergence in reports may signal that the child displays these problems consistently across home and school contexts.

Multiple informants' reports may also diverge in their estimates of mental health. To continue with the problem behavior example, a parent and teacher may differ in their reports such that the teacher's report indicates relatively high levels of problem behavior, whereas the parent's report indicates relatively low levels of such behavior. Such divergence in reports, for instance, may reflect that the child displays problem behavior to a far greater degree at school than at home. If so, then the reasons for the divergence may reflect meaningful variations in the child's problem behavior across relevant contexts (i.e., Diverging Operations; Fig. 1b). Conversely, the reports may not reflect any meaningful divergence, and instead could reflect methodological differences between the informants' reports (e.g., item content, response options, psychometric properties). These methodological factors could parsimoniously explain the divergence between reports (i.e., Compensating Operations; Fig. 1c), and as a result could provide justification for procedures to integrate multi-informant data that assume the lack of convergence among reports reflects measurement error (e.g., structural equations modeling; AND/OR rules; selection of primary outcome measures; De Los Reyes et al. 2015b).

We have developed versions of the Operations Triad Model to understand multi-informant assessments of mental health in relation to contextual variations in observed behavior (De Los Reyes et al. 2013e), and more recently in relation to variations in physiological processes (De Los Reyes and Aldao 2015). In line with prior work, a third aim of this Special Issue is to advance a version of the Operations Triad Model that is modified for use in interpreting multi-informant assessments of family functioning. Such a framework might not only guide hypothesis testing with multi-informant assessments in this area, but also inform the selection of measurement and analytic models.

\section{The Present Special Issue}

Overall, innovative theoretical, measurement, and analytic developments in multi-informant assessments of psychological constructs may inform advancements in using and interpreting adolescents' and parents' reports of assessments of family functioning. Researchers in this area would benefit from a collection of articles that leverage these advancements. To this end, in this Special Issue we address 


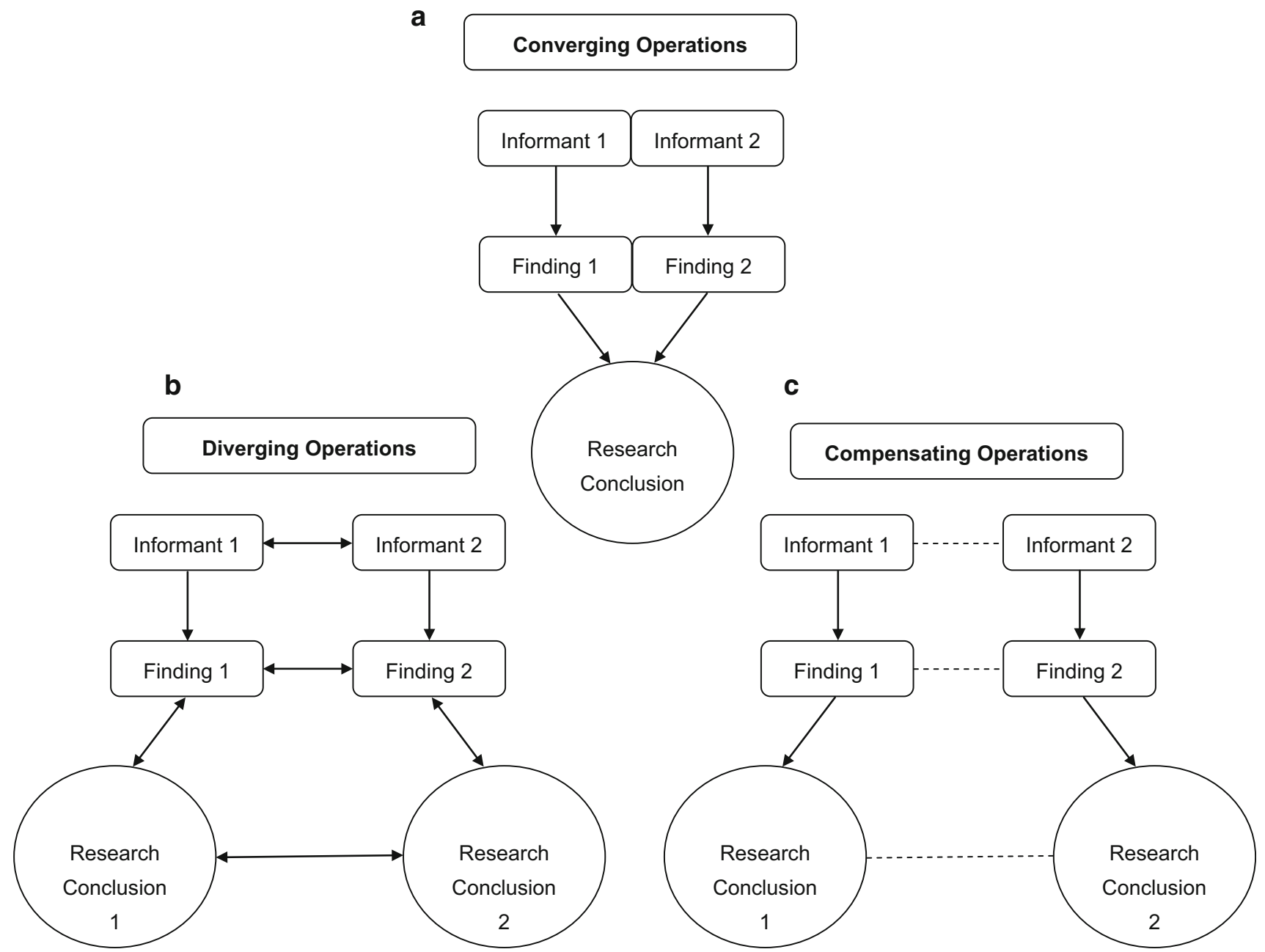

Fig. 1 Originally published in De Los Reyes et al. (2013e): Graphical representation of the research concepts that comprise the Operations Triad Model. The top half (a) represents Converging Operations: a set of measurement conditions for interpreting patterns of findings based on the consistency within which findings yield similar conclusions. The bottom half denotes two circumstances within which researchers identify discrepancies across empirical findings derived from multiple informants' reports and thus discrepancies in the research conclusions drawn from these reports. On the left (b) is a graphical representation of Diverging Operations: a set of measurement conditions for interpreting patterns of inconsistent findings based on hypotheses about variations in the behavior(s) assessed. The solid lines linking informants' reports, empirical

four aims. First, we provide a guiding conceptual framework for using and interpreting multi-informant assessments of family functioning. Second, we report state-ofthe-art scholarship on adolescents' and parents' reports of family functioning using the latest methods for measuring and analyzing patterns of convergence and divergence between these reports. Third, we report research on the measurement invariance of adolescents' and parents' reports of family functioning. Collectively, this research includes diverse areas of study. Fourth, commentaries by Lerner and Rescorla outline directions for future research findings derived from these reports, and conclusions based on empirical findings denote the systematic relations among these three study components. Further, the presence of dual arrowheads in the figure representing Diverging Operations conveys the idea that one ties meaning to the discrepancies among empirical findings and research conclusions and thus how one interprets informants' reports to vary as a function of variation in the behaviors being assessed. Lastly, on the right (c) is a graphical representation of Compensating Operations: a set of measurement conditions for interpreting patterns of inconsistent findings based on methodological features of the study's measures or informants. The dashed lines denote the lack of systematic relations among informants' reports, empirical findings, and research conclusions

on using and interpreting multi-informant assessments of family functioning and their links to adolescent adjustment.

\section{Applying the Operations Triad Model to Adolescent-Parent Reports of Family Functioning}

As described previously, we originally designed the Operations Triad Model to "make sense" of or understand patterns of convergence and divergence between informants' reports of mental health. In particular, we focused 
on detecting when patterns among these reports reflect meaningful variations in mental health within and across relevant social contexts. In order to understand patterns among multiple informants' reports, we designed the Operations Triad Model with a focus on examining such reports in reference to independent assessments of the target person's behavior within and across multiple social contexts (De Los Reyes et al. 2013e). Examples of these independent assessments include performance on laboratory tasks designed to reflect behavior at school or the workplace, or naturalistic observations of the target person's behavior at home. To continue with our previous example, parents and teachers typically observe children's behavior in home and school contexts, respectively. Thus, independent assessments used to make sense of patterns of parent and teacher reports ought to measure behaviors that typically manifest in home and school contexts. In this way, one could examine whether the patterns of convergence and divergence between parent and teacher reports "match" the patterns of behavior observed on these independent assessments (see also De Los Reyes et al. 2009).

\section{Conceptual Overview}

A key element of the Operations Triad Model involves the use of independent criterion measures to test the meaning of patterns of convergence and/or divergence between informants' reports. With some modification, we can generalize this element of the Operations Triad Model to understanding adolescents' and parents' reports of family functioning. Specifically, we previously discussed that assessments of family functioning often also incorporate measures of adolescent, parent, and/or family psychosocial functioning. The idea with these assessments is that often domains of family functioning may serve as risk or protective factors for adolescent adjustment. Yet, as mentioned previously, adolescents' and parents' reports of family functioning may vary as to whether they converge or diverge on estimates of such functioning. Further, displays of family functioning domains, by definition, tend to occur within the adolescent-parent interactional context. As we discuss below, what this means is that only under limited circumstances would divergence between these reports signal that one informant has access to observations of family functioning behaviors that the other informant does not. Thus, between adolescents' and parents' reports about the family, observed patterns of convergence and divergence may reflect meaningful aspects of psychosocial and/or family functioning, rather than contextual variations in behavior. For the purposes of our discussion, we will focus on aspects of adolescent development or the adolescent-parent relationship. For instance, as we discuss below, in some cases convergence between reports may reflect the presence of family environment factors that either protect against or pose risk for the development of poor psychosocial outcomes. We focus on adolescent development and the adolescent-parent relationship, in light of the empirical support for focusing on these domains (e.g., Laird and De Los Reyes 2013; Lippold et al. 2011, 2013, 2014). That being said, other domains may also be relevant to understanding patterns of convergence and/or divergence between adolescents' and parents' reports about the family (e.g., parents' psychosocial functioning).

The Operations Triad Model can inform assessments of family functioning by providing researchers with hypothesis-generating tools for understanding patterns of adolescents' and parents' reports of family functioning and their links to criterion variables, such as independent assessments of domains relevant to adolescent adjustment. In Fig. 2, we graphically depict this key element of our use of the Operations Triad Model for understanding patterns of adolescents' and parents' reports of family functioning, and whether these patterns between reports reflect converging operations (2a), diverging operations (2b), or compensating operations (2c). Below, we discuss examples of patterns of adolescents' and parents' reports of family functioning and when they might reflect these operations.

\section{Converging Operations: When Adolescents' and Parents' Reports Converge on Relatively High Levels of Protective Factors}

As mentioned previously, prior work points to substantial dyad-level variations in magnitudes of convergence, including informant dyads who converge quite highly in reports of psychological phenomena (e.g., De Los Reyes et al. 2009, 2013a, 2016a; Lippold et al. 2011, 2013, 2014). What might convergence between these reports reflect? In the case of convergence between adolescents' and parents' reports of family functioning, such convergence may reflect aspects of the family environment that either protect against or pose risk for the development and/or maintenance of poor psychosocial outcomes among adolescents. In Fig. 3, we graphically depict these possibilities.

First, when adolescents and their parents converge in reports of relatively high levels of factors that protect against the development of psychosocial maladjustment (e.g., parental knowledge and acceptance), this convergence tends to predict lower levels of adolescent maladjustment, relative to other reporting patterns (e.g., divergence between reports; Laird and De Los Reyes 2013; Lippold et al. 2013). This research supports the idea that convergence between adolescent and parent reports reflects their consonance in understanding of family dynamics or their relationship (De Los Reyes et al. 2013c; Goodman 


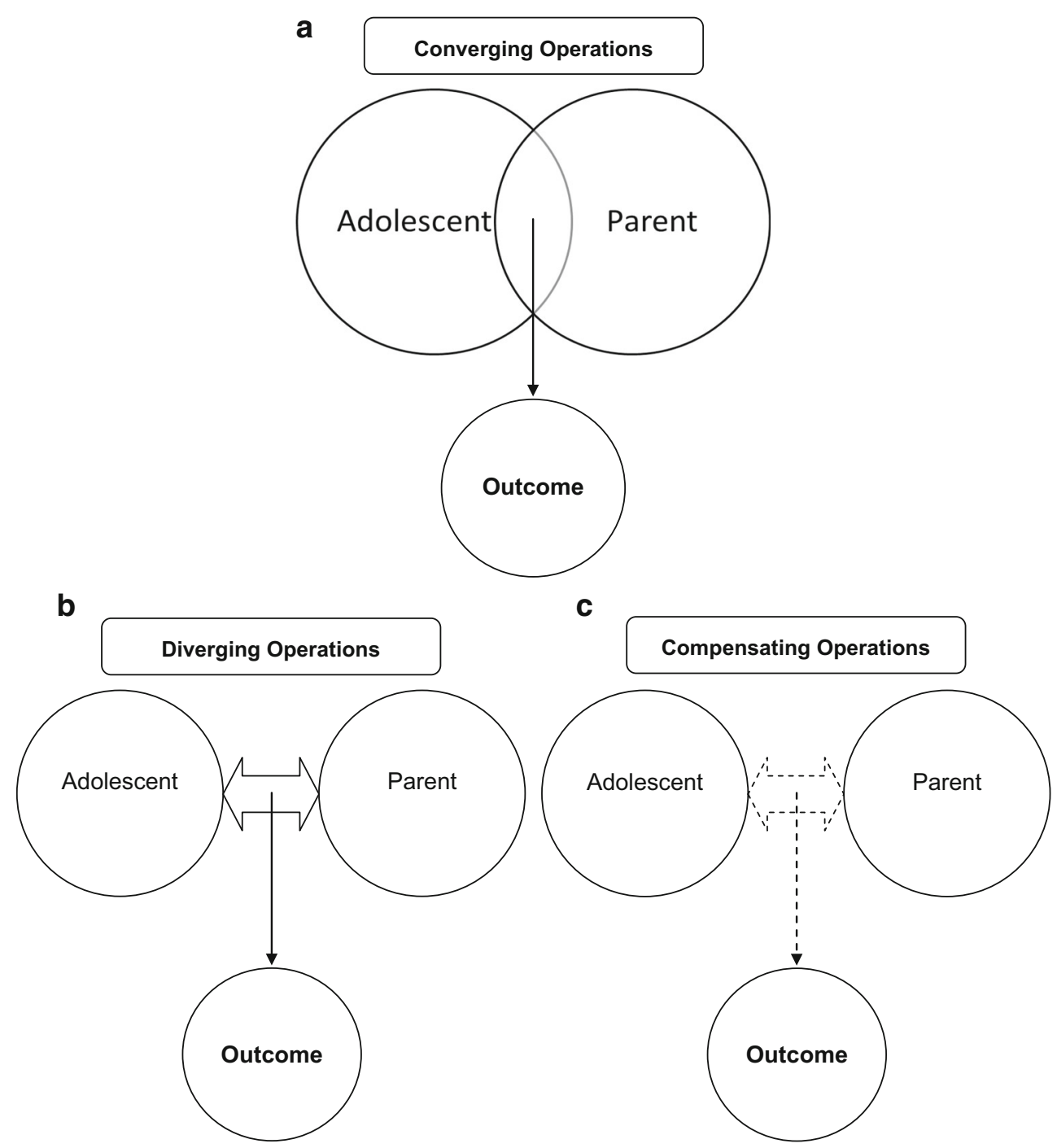

Fig. 2 Graphical depiction of adaptations to the Operations Triad Model for use in interpreting adolescent-parent assessments of family functioning and their links to criterion variables reflecting adolescent adjustment. Consistent with Fig. 1, we graphically depict

et al. 2010). In support of this interpretation, consider that low adolescent-parent discrepant views about the family relate to high performance on objective indices of emotion recognition (De Los Reyes et al. 2013c). As such, sometimes convergence may serve as a marker for factors that buffer against the development of adolescent maladjustment, such as parental acceptance of the adolescent or general consonance in understanding of family dynamics. We graphically depict these ideas in Fig. 3a.

\section{Converging Operations: When Adolescents' and Parents' Reports Converge on Relatively High Levels of Risk Factors}

A second possibility with converging adolescent-parent reports is that the convergence signals relatively high levels interpretations of adolescents' and parents' reports and their links to adolescent adjustment consistent with Converging Operations (a), Diverging Operations (b), and Compensating Operations (c)

of risk for adolescent maladjustment. We graphically depict this form of convergence in Fig. 3b. For instance, consider an adolescent and parent who both estimate the presence of a risk factor for adolescent maladjustment (e.g., low parental knowledge of adolescents' whereabouts and activities, high inconsistent parenting, high adolescent-parent conflict). In this case, the adolescent-parent dyad's convergence on this risk factor may be a marker for the high severity or level of that risk factor. That is, relative to reports that diverge from one another, if both members of the dyad report relatively high levels of a risk-prone family domain, then it is more likely the case that high levels of the domain have either been present for a long time, or consistently manifest across adolescent-parent interactions.

Two lines of recent work support these ideas. For example, in adolescent mental health assessments, we have 


\section{Reports of Protective Factors}

a

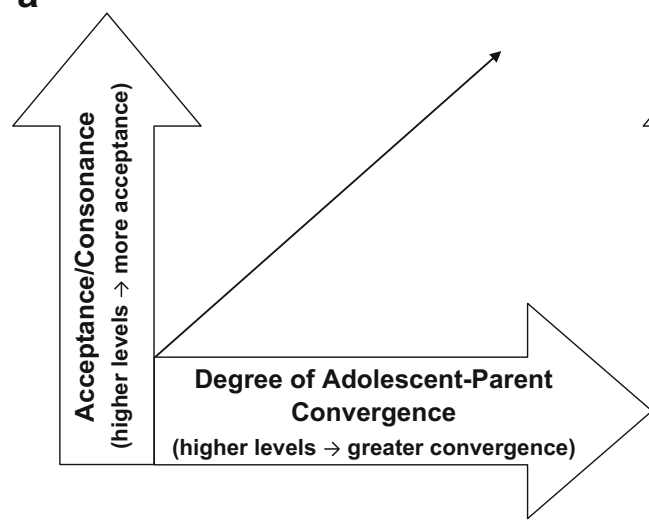

Fig. 3 Graphical depiction of Converging Operations, adapted for use in interpreting adolescent-parent assessments of family functioning and their links to adolescent adjustment, depending on whether

\section{Reports of Risk Factors}

b

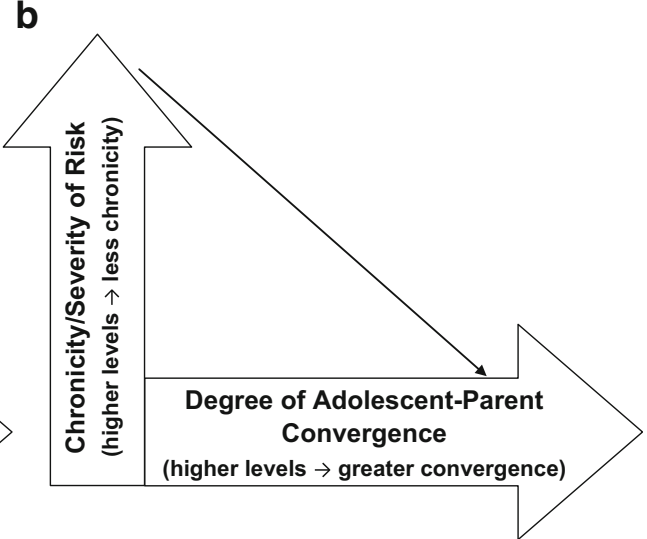

the patterns of convergence serve as protective factors (a) or risk factors (b) for adolescent maladjustment

found that when two parents (i.e., informants who observe adolescents in the same context) converge on reports of relatively high adolescent mental health concerns, the adolescent both displays greater hostility within observed family interactions, and self-reports greater mental health concerns, relative to adolescents whose parents do not converge in their reports about adolescent mental health (De Los Reyes et al. 2016a). Consistent with this work in mental health, in recent developmental work, adolescentparent dyads that converge on relatively low levels of parental knowledge have adolescents who are at particularly high risk for developing substance use (e.g., Lippold et al. 2013, 2014). Consequently, sometimes convergence between reports may serve as a marker for factors that pose risk for the development of adolescent maladjustment (Fig. 3b).

\section{Diverging Operations: When Divergence between Adolescents' and Parents' Reports Reflects Adaptive Family Processes}

Among the substantial dyad-level variations in patterns of informants' reports (e.g., De Los Reyes et al. 2009, 2013a, 2016a; Lippold et al. 2011, 2013, 2014), adolescents and parents might diverge quite highly in reports of family functioning. What might this divergence reflect? As with convergence, divergence between adolescents' and parents' reports of family functioning might reflect aspects of the family environment that portend either adaptive or maladaptive outcomes. In Fig. 4, we graphically depict these possibilities.

First, divergence between adolescents' and parents' reports of the family may reflect adaptive family processes, particularly with regard to the adolescent. We graphically depict this form of divergence in Fig. 4a. For example, in early adolescence, the adolescent typically pushes for greater autonomy and family relationships are renegotiated (Smetana et al. 2006). Cognitive advances take place as well, allowing for the adolescent to question others' perspectives (Spear 2000). During mid-adolescence, adolescents begin to resolve these developmental tasks, and experience improvements in cognitive and emotional functioning, as well as increased autonomy. Relatedly, discrepancies between adolescent and parent views of the family may play a functional role in adolescent autonomy development. During early adolescence, the adolescent's natural developmental push for autonomy and independence may manifest in differing perceptions between adolescents and their parents. Moreover, exposure to these discrepant views subsequently may allow adolescents to become more emotionally detached from the family and over time, enable them to ultimately process the realignment of family relationships (Holmbeck and O'Donnell 1991; Montemayor and Flannery 1990; Shek 2002; Steinberg 1990, 1991). These normative changes might account for the finding that during early adolescence, adolescents tend to view the family in relatively negative ways in comparison to their parents (e.g., Ohannessian and De Los Reyes 2014; Ohannessian et al. 2000). In fact, relative to parents' reports, adolescents report lower levels of family satisfaction and family cohesion (Ohannessian et al. 2000, 1995), as well as higher levels of communication problems (De Los Reyes et al. 2016b; Laird and De Los Reyes 2013; Reynolds et al. 2011; Yu et al. 2006). Consequently, increased divergence between adolescents' and parents' reports may relate to an increased mastering of adolescent normative developmental tasks. In this way, divergence between adolescents' and parents' reports of 
$\underline{\text { Divergence } \rightarrow \text { Adaptive Outcomes }}$

a

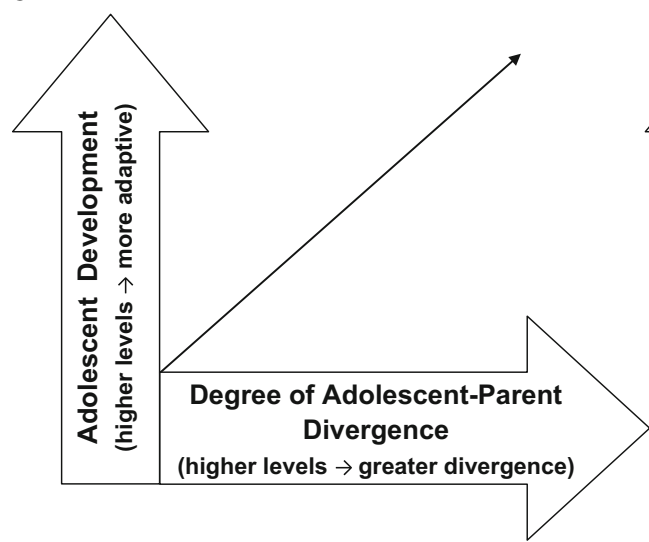

Divergence $\rightarrow$ Maladaptive Outcomes

b

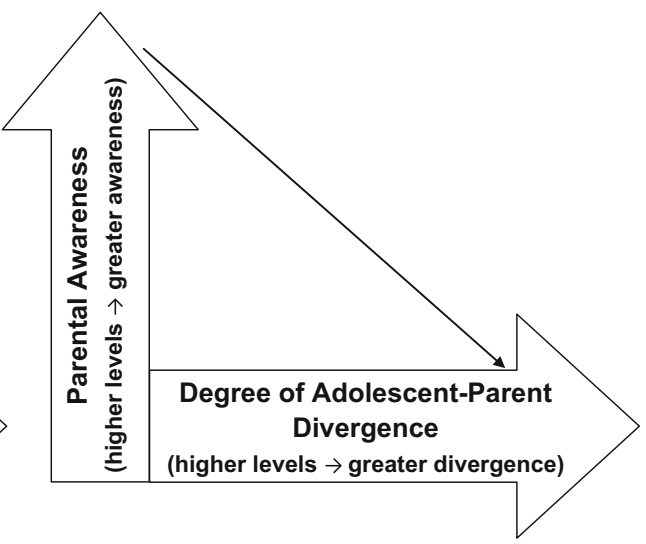

Fig. 4 Graphical depiction of Diverging Operations, adapted for use in interpreting adolescent-parent assessments of family functioning and their links to adolescent adjustment, depending on whether the

the family may predict adaptive adolescent adjustment outcomes.

\section{Diverging Operations: When Divergence between Adolescents' and Parents' Reports Reflects Maladaptive Family Processes}

A second possibility with divergence between adolescent-parent reports is that the divergence reflects maladaptive family processes. In this example, we will focus on a form of maladaptive family functioning, graphically depicted in Fig. 4b. Specifically, divergence between adolescents' and parents' reports may reflect maladaptive processes if the mechanism underlying the divergence is that the parent has a lack of awareness of key aspects of the adolescent's life, whereabouts, and activities (Goodman et al. 2010). This lack of awareness may, in turn, hinder the parent's ability to protect the adolescent from harm or create an environment that lowers the likelihood that the adolescent engages in problematic behavior (e.g., through appropriate and consistent limit-setting and curfew times).

Two lines of recent work support these ideas. For example, when parents report relatively low levels of adolescent pubertal development and adolescents self-report relatively high levels of such development, this divergence predicts increased adolescent antisocial behavior, relative to other adolescent-parent reporting patterns (e.g., both adolescent and parent report relatively high pubertal development; Laird and De Los Reyes 2013). Relatedly, when a parent reports relatively high knowledge about an adolescent's whereabouts and activities and the adolescent reports that their parent has relatively low knowledge of such activities, this divergence places the adolescent at increased risk for developing substance use problems, relative to other patterns of divergence predict adaptive adolescent outcomes (a) or maladaptive adolescent outcomes (b)

adolescent-parent reporting patterns (e.g., Lippold et al. 2013, 2014). Consequently, divergence may also serve as a marker for family processes that pose risk for the development of adolescent maladjustment.

Importantly, adaptive and maladaptive manifestations of divergence should not be seen as competing interpretations of divergence between adolescents' and parents' reports about the family. In fact, both displays of divergence may coexist in the form of dyad-level variations in trajectories of adolescents' and parents' reports across adolescent development. We graphically depict these possibilities in Fig. 5. For instance, adolescents and parents may display a normative trajectory of increasing discrepancies between their perceptions of the family throughout early adolescence, before plateauing and declining in mid-to-late adolescence. Such a trajectory might reflect the adaptive family processes and their links to positive adolescent outcomes depicted in Fig. 4a. However, not all adolescentparent dyads may experience this normative course of discrepant views of the family. A distinct trajectory might involve adolescents and parents exhibiting an atypical course of stable and high levels of discrepant views. This trajectory might reflect the maladaptive family processes and negative adolescent outcomes depicted in Fig. 4b. Such a trajectory might manifest if within the early-adolescent period, the dyad displays family-level risks (e.g., chronically low parental awareness), and the adolescent displays behavioral, cognitive, and/or emotional dysfunction. Yet another trajectory might involve displays of stable and low levels of discrepant views between adolescents and parents. These chronically low discrepancies also may be problematic and reflect failure of the adolescent to master normal developmental tasks (e.g., autonomy). We 


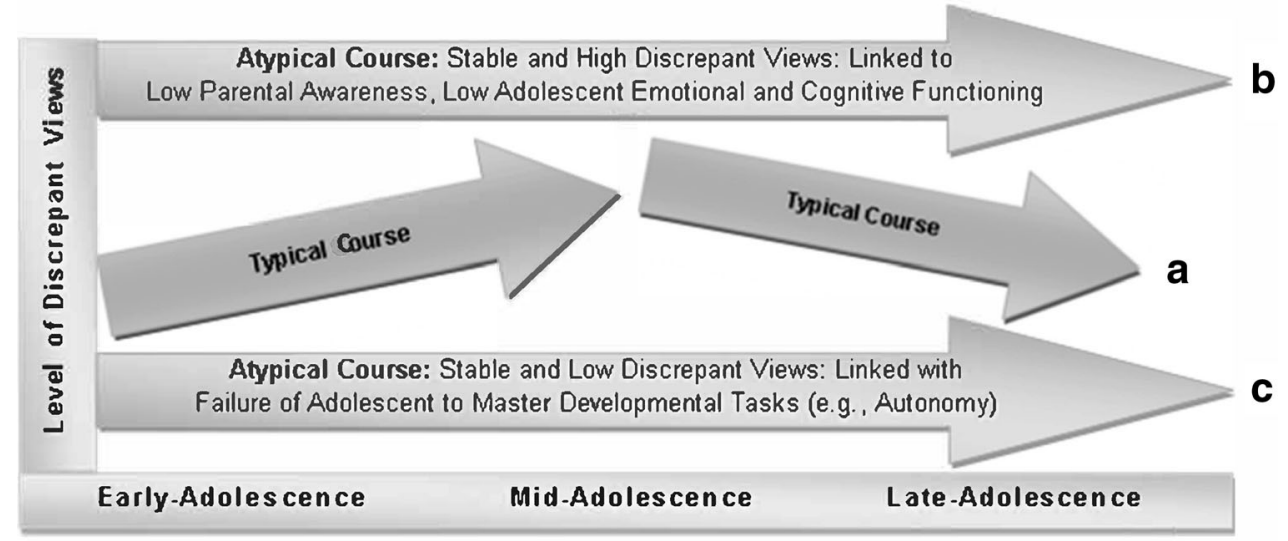

Fig. 5 Graphical depiction of Diverging Operations, adapted for use in interpreting longitudinal trajectories of discrepancies between adolescent and parent views of the family and their links to adolescent adjustment. This conceptualization of Diverging Operations allows for the possibility of patterns of divergence to reflect either adaptive

present these sets of trajectories merely as an example of how adaptive and maladaptive displays of adolescentparent divergence in reports of the family might co-exist in the same conceptualization of divergence.

\section{Compensating Operations}

In generalizing the Operations Triad Model to understanding adolescents' and parents' reports of family functioning, it is important to highlight the possibility that sometimes divergence between adolescents' and parents' reports of family functioning may be parsimoniously explained by methodological factors inherent in the measures informants complete or the assessment process generally. We graphically depict this possibility in Fig. 6. For instance, researchers studying a sample of families might observe that parents in the sample provided relatively more reliable and consistent reports about the family functioning domain(s) assessed, relative to the reports provided by adolescents in the sample. Here, measurement error might explain why divergence between reports arose, rather than the presence of any true or meaningful differences between adolescent or parent views of the family (see De Los Reyes 2011, 2013). The content of the measures that adolescents and parents complete might also differ, such as item content or response options, and these differences could account for divergence between reports. As mentioned previously, still another possibility is that divergence between adolescents' and parents' reports manifests as a function of measurement invariance effects (i.e., adolescents' and parents' reports do not carry the same psychometric properties). Regardless of the methodological factor(s), compensating operations produces two results. First, its presence eliminates the possibility of divergence meaningfully relating to criterion variables reflecting or maladaptive family processes. Specifically, in the figure we depict three trajectories of discrepancies between adolescent and parent views about the family: a increase steadily and then decrease over the course of adolescent development, or display a chronic course of b relatively high or $\mathbf{c}$ relatively low discrepant views

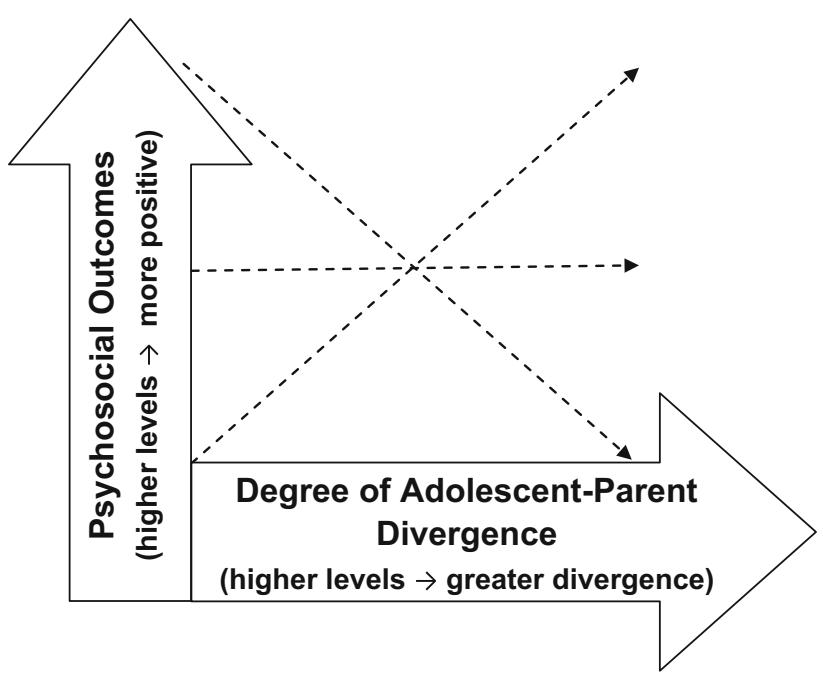

Fig. 6 Graphical depiction of Compensating Operations, adapted for use in interpreting adolescent-parent assessments of family functioning and their links to adolescent adjustment

adolescent adjustment. Second, the presence of compensating operations provides researchers with justification to use measurement or analytic techniques that focus on the convergence between reports and treat the divergence as measurement error (e.g., structural equations modeling; AND/ OR rules; selection of primary outcome measures; De Los Reyes et al. 2015b).

\section{Overview of Special Issue Articles}

The articles in this Special Issue illustrate the potential for multi-informant assessments of family functioning to meaningfully inform research and theory on the links between family processes and adolescent adjustment. 
Indeed, across various study designs, family functioning domains, measurement methods, and analytic techniques, these studies illustrate a variety of approaches one can take to understand patterns of convergence and divergence between adolescents' and parents' reports about the family. Further, this work may inform the design of future studies aiming to improve our understanding of discrepancies between adolescents' and parents' reports across a variety of areas of adolescent and family research and theory.

We highlight several of the Special Issue's empirical articles that address the specific aims described previously. In their study, Borelli and colleagues leveraged polynomial regression techniques to uncover links between divergence in preadolescent and parent views of the family and preadolescents' biological and cognitive reactions to stress. A number of other studies used polynomial regression techniques to address questions relevant to the psychosocial functioning of adolescents in Hong Kong (Leung, Shek, and Li), the Netherlands (Nelemans et al.), and the United States (Human, Dirks, DeLongis, and Chen). Further, one study used the polynomial regression approach to understand convergence between adolescents' and parents' reports about the family and its links to parental psychosocial functioning (Ohannessian, Laird, and De Los Reyes). Two studies applied personcentered models of data analysis to understand patterns and correlates of adolescent-parent reports of the family (Rote and Smetana; Skinner and McHale), one study illustrated the use of tests of measurement invariance to interpret differences between youth and parent reports about parenting behaviors (Russell, Graham, Neill, and Weems), and one study reported findings of a meta-analysis of correspondence between children's and adolescents' and parents' reports of parenting and moderators of this correspondence (Korelitz and Garber).

In this introductory article, we provided an empirical and conceptual overview of the basis for this Special Issue. We also advanced a theoretical framework for guiding hypothesis testing when understanding and interpreting multi-informant assessments of family functioning and their links to adolescent adjustment. In doing so, we omitted discussion of key directions for future research. Thus, in addition to the empirical articles two commentaries focus on these issues. Specifically, Lerner discusses the research and theoretical implications of the Special Issue and outlines directions for future research in applied developmental science. Further, Rescorla discusses the Special Issue in the context of cross-cultural assessments of the family and adolescent mental health.

\section{Conclusion}

Researchers who study adolescent and family functioning learn about this functioning by collecting subjective reports from adolescents and their parents. As with many other areas of adolescent and family research, studies consistently find that these reports tend to yield relatively low levels of correspondence in estimates of family functioning. However, underlying these low levels of correspondence there exist substantial variability among adolescent-parent dyads as to whether they converge or diverge in estimates of family functioning. In recent years, work reveals that these patterns of converging or diverging reports may yield important information about adolescent adjustment. In fact, this work is part of a larger literature seeking to understand and interpret multi-informant assessments of psychological phenomena, namely mental health. Yet, recent innovations in conceptualizing, measuring, and analyzing multi-informant mental health assessments might meaningfully inform efforts to understand these assessments as conducted in family-based research. In this introductory article to a Special Issue on these topics, we advanced a guiding conceptual framework for using and interpreting multi-informant assessments of family functioning. Within this Special Issue, we report research on adolescent-parent reports of family functioning that leverages the latest methods for measuring and analyzing patterns of convergence and divergence between reports. We also report research on the measurement invariance of adolescents' and parents' reports of family functioning. Finally, commentaries by Lerner and Rescorla provide a context for understanding the relevance of this work for applied developmental science, as well as for cross-cultural assessment of family functioning and adolescent mental health. We hope this work inspires you to develop ideas for why families recruited in your research view the family in converging or diverging ways, and how these patterns of convergence and divergence relate to crucial aspects of adolescents' lives, their parents, and the adolescent-parent relationship.

Acknowledgments This work was supported, in part, by NSF grant number 1461392 awarded to Andres De Los Reyes, and by NSF grant number 1461394 awarded to Christine McCauley Ohannessian.

Authors' Contributions AD and CMO co-wrote this article. Both of the authors read and approved the final manuscript.

Conflicts of interest The authors report no conflict of interests.

\section{References}

Achenbach, T. M. (2006). As others see us: Clinical and research implications of cross-informant correlations for psychopathology. Current Directions in Psychological Science, 15, 94-98. doi:10.1111/j.0963-7214.2006.00414.x.

Achenbach, T. M., Krukowski, R. A., Dumenci, L., \& Ivanova, M. Y. (2005). Assessment of adult psychopathology: Meta-analyses and implications of cross-informant correlations. Psychological Bulletin, 131, 361-382. doi:10.1037/0033-2909.131.3.361. 
Achenbach, T. M., McConaughy, S. H., \& Howell, C. T. (1987). Child/adolescent behavioral and emotional problems: Implications of cross-informant correlations for situational specificity. Psychological Bulletin, 101, 213-232. doi:10.1037/0033-2909. 101.2.213.

Aldao, A., \& De Los Reyes, A. (2015). Commentary on the special issue. A practical guide for translating basic research on affective science to implementing physiology in clinical child and adolescent assessments. Journal of Clinical Child and Adolescent Psychology, 44, 341-351. doi:10.1080/15374416.2014. 895942.

Alfano, C. A., Patriquin, M. A., \& De Los Reyes, A. (2015). Subjective-objective sleep comparisons and discrepancies among clinically-anxious and healthy children. Journal of Abnormal Child Psychology, 43, 1343-1353. doi:10.1007/ s10802-015-0018-7.

Ary, D. V., Duncan, T. E., Biglan, A., Metzler, C. W., Noell, J. W., \& Smolkowski, K. (1999). Development of adolescent problem behavior. Journal of Abnormal Child Psychology, 27, 141-150. doi:10.1023/A:1021963531607.

Augenstein, T. M., Thomas, S. A., Ehrlich, K. B., Daruwala, S. E., Reyes, S. M., Chrabaszcz, J. S., \& De Los Reyes, A. (2016). Comparing multi-informant assessment measures of parental monitoring and their links with adolescent delinquent behavior. Parenting: Science and Practice, 16, 164-186. doi:10.1080/ 15295192.2016.1158600.

Borelli, J. L., Smiley, P. A., Rasmussen, H. F., \& Gómez, A. (this issue). Is it about me, you, or us? Stress reactivity correlates of discrepancies in we-talk among parents and preadolescent children. Journal of Youth and Adolescence. doi: 10.1007/ s10964-016-0459-5.

Cohen, S., Masyn, K., Mastergeorge, A., \& Hessl, D. (2015). Psychophysiological responses to emotional stimuli in children and adolescents with autism and fragile $\times$ syndrome. Journal of Clinical Child and Adolescent Psychology, 44, 250-263. doi:10. 1080/15374416.2013.843462.

Darling, N., \& Steinberg, L. (1993). Parenting style as context: An integrative model. Psychological Bulletin, 113, 487-496. doi:10. 1037/0033-2909.113.3.487.

De Los Reyes, A. (2011). Introduction to the special section. More than measurement error: Discovering meaning behind informant discrepancies in clinical assessments of children and adolescents. Journal of Clinical Child and Adolescent Psychology, 40, 1-9. doi:10.1080/15374416.2011.533405.

De Los Reyes, A. (2013). Strategic objectives for improving understanding of informant discrepancies in developmental psychopathology research. Development and Psychopathology, 25, 669-682. doi:10.1017/S0954579413000096.

De Los Reyes, A., \& Aldao, A. (2015). Introduction to the special issue. Toward implementing physiological measures in clinical child and adolescent assessments. Journal of Clinical Child and Adolescent Psychology, 44, 221-237. doi:10.1080/15374416. 2014.891227.

De Los Reyes, A., Alfano, C. A., \& Beidel, D. C. (2011). Are clinicians' assessments of improvements in children's functioning "global"? Journal of Clinical Child and Adolescent Psychology, 40, 281-294. doi:10.1080/15374416.2011.546043.

De Los Reyes, A., Alfano, C. A., Lau, S., Augenstein, T. M., \& Borelli, J. L. (2016a). Can we use convergence between caregiver reports of adolescent mental health to index severity of adolescent mental health concerns? Journal of Child and Family Studies, 25, 109-123. doi:10.1007/s10826-015-0216-5.

De Los Reyes, A., Augenstein, T. M., Aldao, A., Thomas, S. A., Daruwala, S. E., Kline, K., \& Regan, T. (2015a). Implementing psychophysiology in clinical assessments of adolescent social anxiety: Use of rater judgments based on graphical representations of psychophysiology. Journal of Clinical Child and Adolescent Psychology, 44, 264-279. doi:10.1080/ 15374416.2013.859080.

De Los Reyes, A., Augenstein, T. M., Wang, M., Thomas, S. A., Drabick, D. A. G., Burgers, D., \& Rabinowitz, J. (2015b). The validity of the multi-informant approach to assessing child and adolescent mental health. Psychological Bulletin, 141, 858-900. doi:10.1037/a0038498.

De Los Reyes, A., Bunnell, B. E., \& Beidel, D. C. (2013a). Informant discrepancies in adult social anxiety disorder assessments: Links with contextual variations in observed behavior. Journal of Abnormal Psychology, 122, 376-386. doi:10.1037/a0031150.

De Los Reyes, A., Ehrlich, K. B., Swan, A. J., Luo, T. J., Van Wie, M., \& Pabón, S. C. (2013b). An experimental test of whether informants can report about child and family behavior based on settings of behavioral expression. Journal of Child and Family Studies, 22, 177-191. doi:10.1007/s10826-012-9567-3.

De Los Reyes, A., Goodman, K. L., Kliewer, W., \& Reid-Quiñones, K. (2010). The longitudinal consistency of mother-child reporting discrepancies of parental monitoring and their ability to predict child delinquent behaviors two years later. Journal of Youth and Adolescence, 39, 1417-1430. doi:10.1007/s10964009-9496-7.

De Los Reyes, A., Henry, D. B., Tolan, P. H., \& Wakschlag, L. S. (2009). Linking informant discrepancies to observed variations in young children's disruptive behavior. Journal of Abnormal Child Psychology, 37, 637-652. doi:10.1007/s10802-009-93073.

De Los Reyes, A., \& Kazdin, A. E. (2004). Measuring informant discrepancies in clinical child research. Psychological Assessment, 16, 330-334. doi:10.1037/1040-3590.16.3.330.

De Los Reyes, A., \& Kazdin, A. E. (2005). Informant discrepancies in the assessment of childhood psychopathology: A critical review, theoretical framework, and recommendations for further study. Psychological Bulletin, 131, 483-509. doi:10.1037/0033-2909. 131.4.483.

De Los Reyes, A., \& Kazdin, A. E. (2006a). Informant discrepancies in assessing child dysfunction relate to dysfunction within mother-child interactions. Journal of Child and Family Studies, 15, 645-663. doi:10.1007/s10826-006-9031-3.

De Los Reyes, A., Ohannessian, C. M., \& Laird, R. D. (2016b). Developmental changes in discrepancies between adolescents' and their mothers' views of family communication. Journal of Child and Family Studies, 25, 790-797. doi:10.1007/s10826015-0275-7.

De Los Reyes, A., \& Kazdin, A. E. (2006b). Conceptualizing changes in behavior in intervention research: The range of possible changes model. Psychological Review, 113, 554-583. doi:10. 1037/0033-295X.113.3.554.

De Los Reyes, A., Lerner, M. D., Thomas, S. A., Daruwala, S. E., \& Goepel, K. A. (2013c). Discrepancies between parent and adolescent beliefs about daily life topics and performance on an emotion recognition task. Journal of Abnormal Child Psychology, 41, 971-982. doi:10.1007/s10802-013-9733-0.

De Los Reyes, A., Salas, S., Menzer, M. M., \& Daruwala, S. E. (2013d). Criterion validity of interpreting scores from multiinformant statistical interactions as measures of informant discrepancies in psychological assessments of children and adolescents. Psychological Assessment, 25, 509-519. doi:10. 1037/a0032081.

De Los Reyes, A., Thomas, S. A., Goodman, K. L., \& Kundey, S. M. A. (2013e). Principles underlying the use of multiple informants' reports. Annual Review of Clinical Psychology, 9, 123-149. doi:10.1146/annurev-clinpsy-050212-185617.

De Los Reyes, A., Thomas, S. A., Swan, A. J., Ehrlich, K. B., Reynolds, E. K., Suarez, L., Dougherty, L. R., MacPherson, L., \& 
Pabón, S. C. (2012). "It depends on what you mean by 'disagree'”: Differences between parent and child perceptions of parent-child conflict. Journal of Psychopathology and Behavioral Assessment, 34, 293-307. doi:10.1007/s10862-012-9288-3.

Dirks, M. A., Weersing, V. R., Warnick, E., Gonzalez, A., Alton, M., Dauser, C., et al. (2014). Parent and youth report of youth anxiety: Evidence for measurement invariance. Journal of Child Psychology and Psychiatry, 55, 284-291. doi:10.1111/jcpp. 12159.

Duncan, S. C., Duncan, T. E., Biglan, A., \& Ary, D. (1998). Contributions of the social context to the development of adolescent substance use: A multivariate latent growth modeling approach. Drug and Alcohol Dependence, 50, 57-71. doi:10. 1016/S0376-8716(98)00006-4.

Edwards, J. R. (1994). The study of congruence in organizational behavior research: Critique and a proposed alternative. Organizational Behavior and Human Decision Processes, 58, 51-100. doi:10.1006/obhd.1994.1029.

Edwards, J. R. (2002). Alternatives to difference scores: Polynomial regression analysis and response surface methodology. In F. Drasgow \& N. Schmitt (Eds.), Measuring and analyzing behavior in organizations: Advances in measurement and data analysis (pp. 350-400). San Francisco: Jossey-Bass.

Epstein, M. K., Renk, K., Duhig, A. M., Bosco, G. L., \& Phares, V. (2004). Interparental conflict, adolescent behavioral problems, and adolescent competence: Convergent and discriminant validity. Educational and Psychological Measurement, 64, 475-495. doi:10.1177/0013164403258462.

Fjermestad, K. W., Lerner, M. D., McLeod, B. D., Wergeland, G. J. H., Heiervang, E. R., Silverman, W. K., et al. (2016). Therapist-youth agreement on alliance change predicts longterm outcome in CBT for anxiety disorders. Journal of Child Psychology and Psychiatry, 57, 625-632. doi:10.1111/jcpp. 12485.

Franklin, J. C., Jamieson, J. P., Glenn, C. R., \& Nock, M. K. (2015). How developmental psychopathology theory and research can inform the Research Domain Criteria (RDoC) project. Journal of Clinical Child and Adolescent Psychology, 44, 280-290. doi:10. 1080/15374416.2013.873981.

Fung, J. J., \& Lau, A. S. (2010). Factors associated with parent-child (dis)agreement on child behavior and parenting problems in Chinese immigrant families. Journal of Clinical Child and Adolescent Psychology, 39, 314-327. doi:10.1080/ 15374411003691693.

Gatzke-Kopp, L. M., Greenberg, M., \& Bierman, K. (2015). Children's parasympathetic reactivity to specific emotions moderates response to intervention for early-onset aggression. Journal of Clinical Child and Adolescent Psychology, 44, 291-304. doi:10.1080/15374416.2013.862801.

Gonzales, N. A., Cauce, A. M., \& Mason, C. A. (1996). Interobserver agreement in the assessment of parental behavior and parentadolescent conflict: African American mothers, daughters, and independent observers. Child Development, 67, 1483-1498. doi: $10.2307 / 1131713$.

Goodman, K. L., De Los Reyes, A., \& Bradshaw, C. P. (2010). Understanding and using informants' reporting discrepancies of youth victimization: A conceptual model and recommendations for research. Clinical Child and Family Psychology Review, 13, 366-383. doi:10.1007/s10567-010-0076-x.

Gross, T. J., Fleming, C. B., Mason, W. A., \& Haggerty, K. P. (2016). Alabama Parenting Questionnaire-9: Longitudinal measurement invariance across parents and youth during the transition to high school. Assessment. doi:10.1177/1073191115620839.

Guion, K., Mrug, S., \& Windle, M. (2009). Predictive value of informant discrepancies in reports of parenting: Relations to early adolescents' adjustment. Journal of Abnormal Child Psychology, 37, 17-30. doi:10.1007/s10802-008-9253-5.

Holmbeck, G. N., \& O'Donnell, K. (1991). Discrepancies between perceptions of decision making and behavioral autonomy. New Directions for Child and Adolescent Development, 51, 51-69. doi:10.1002/cd.23219915105.

Human, L. J., Dirks, M. A., DeLongis, A., \& Chen, E. (this issue). Congruence and incongruence in adolescents' and parents' perceptions of the family: Using response surface analysis to examine links with adolescents' psychological adjustment. Journal of Youth and Adolescence. doi: 10.1007/s10964-0160517-z.

Hunsley, J., \& Mash, E. J. (2007). Evidence-based assessment. Annual Review of Clinical Psychology, 3, 29-51. doi:10.1146/ annurev.clinpsy.3.022806.091419.

Janssens, A., Goossens, L., Van Den Noortgate, W., Colpin, H., Verschueren, K., \& Van Leeuwen, K. (2015). Parents' and adolescents' perspectives on parenting: Evaluating conceptual structure, measurement invariance, and criterion validity. Assessment, 22, 473-489. doi:10.1177/1073191114550477.

Kerr, M., \& Stattin, H. (2000). What parents know, how they know it, and several forms of adolescent adjustment: Further support for a reinterpretation of monitoring. Developmental Psychology, 36, 366-380. doi:10.1037/0012-1649.36.3.366.

Korelitz, K. E., \& Garber, J. (this issue). Congruence of parents' and children's perceptions of parenting: A meta-analysis. Journal of Youth and Adolescence. (in press).

Kraemer, H. C., Measelle, J. R., Ablow, J. C., Essex, M. J., Boyce, W. T., \& Kupfer, D. J. (2003). A new approach to integrating data from multiple informants in psychiatric assessment and research: Mixing and matching contexts and perspectives. American Journal of Psychiatry, 160, 1566-1577. doi:10.1176/appi.ajp. 160.9.1566.

Laird, R. D., \& De Los Reyes, A. (2013). Testing informant discrepancies as predictors of early adolescent psychopathology: Why difference scores cannot tell you what you want to know and how polynomial regression may. Journal of Abnormal Child Psychology, 41, 1-14. doi:10.1007/s10802-012-9659-y.

Laird, R. D., \& LaFleur, L. K. (2016). Disclosure and monitoring as predictors of mother-adolescent agreement in reports of early adolescent rule-breaking behavior. Journal of Clinical Child and Adolescent Psychology, 45, 188-200. doi:10.1080/15374416. 2014.963856.

Laird, R. D., \& Weems, C. F. (2011). The equivalence of regression models using difference scores and models using separate scores for each informant: Implications for the study of informant discrepancies. Psychological Assessment, 23, 388-397. doi:10. 1037/a0021926.

Laursen, B., Coy, K. C., \& Collins, W. A. (1998). Reconsidering changes in parent-child conflict across adolescence: A metaanalysis. Child Development, 69, 817-832. doi:10.1111/j.14678624.1998.tb06245.x.

Leitzke, B. T., Hilt, L. M., \& Pollak, S. D. (2015). Maltreated youth display a blunted blood pressure response to an acute interpersonal stressor. Journal of Clinical Child and Adolescent Psychology, 44, 305-313. doi:10.1080/15374416.2013.848774.

Leung, J. T. Y., Shek, D. T. L., \& Li, L. (this issue). Mother-child discrepancy in perceived family functioning and adolescent developmental outcomes in families experiencing economic disadvantage in Hong Kong. Journal of Youth and Adolescence. doi: 10.1007/s10964-016-0469-3.

Lippold, M. A., Greenberg, M. T., \& Collins, L. M. (2013). Parental knowledge and youth risky behavior: A person oriented approach. Journal of Youth and Adolescence, 42, 1732-1744. doi:10.1007/s10964-012-9893-1. 
Lippold, M. A., Greenberg, M. T., \& Collins, L. M. (2014). Youths' substance use and changes in parental knowledge-related behaviors during middle school: A person-oriented approach. Journal of Youth and Adolescence, 43, 729-744. doi:10.1007/ s10964-013-0010-x.

Lippold, M. A., Greenberg, M. T., \& Feinberg, M. E. (2011). A dyadic approach to understanding the relationship of maternal knowledge of youths' activities to youths' problem behavior among rural adolescents. Journal of Youth and Adolescence, 40, 1178-1191. doi:10.1007/s10964-010-9595-5.

McLaughlin, K. A., Rith-Najarian, L., Dirks, M. A., \& Sheridan, M. A. (2015). Low vagal tone magnifies the association between psychosocial stress exposure and internalizing psychopathology in adolescents. Journal of Clinical Child and Adolescent Psychology, 44, 314-328. doi:10.1080/15374416.2013.843464.

Meyer, A., Lerner, M. D., De Los Reyes, A., Laird, R. D., \& Hajcak, G. (2016). Considering ERP difference scores as individual difference measures: Issues with subtraction and alternative approaches. Psychophysiology. (in press).

Montemayor, R., \& Flannery, D. J. (1990). Making the transition from childhood to early adolescence. In R. Montemayor, G. R. Adams, \& T. P. Gullotta (Eds.), From childhood to adolescence: A transitional period? (pp. 291-301). Thousand Oaks, CA: Sage Publications.

Nelemans, S. A., Branje, S. J. T., Hale III, W. W., Goosens, L., Koot, H. M., Oldehinkel, A. J., \& Meeus, W. H. J. (this issue). Discrepancies between perceptions of the parent-adolescent relationship and early adolescent depressive symptoms: An illustration of polynomial regression analysis. Journal of Youth and Adolescence. doi: 10.1007/s10964-016-0503-5.

Ohannessian, C. M. (2012). Discrepancies in adolescents' and their mothers' perceptions of the family and adolescent externalizing problems. Family Science, 3, 135-140. doi:10.1080/19424620. 2012.704596.

Ohannessian, C. M., Laird, R. D., \& De Los Reyes, A. (this issue). Discrepancies in adolescents' and mother's perceptions of the family and mothers' psychological symptomatology. Journal of Youth and Adolescence. doi: 10.1007/s10964-016-0477-3.

Ohannessian, C. M., \& De Los, Reyes A. (2014). Discrepancies in adolescents' and their mothers' perceptions of the family and adolescent anxiety symptomatology. Parenting: Science and Practice, 14, 1-18. doi:10.1080/15295192.2014.870009.

Ohannessian, C. M., Lerner, R. M., Lerner, J. V., \& von Eye, A. (1995). Discrepancies in adolescents' and parents' perceptions of family functioning and adolescent emotional adjustment. Journal of Early Adolescence, 15, 490-516. doi:10.1177/ 0272431695015004006.

Ohannessian, C. M., Lerner, J. V., Lerner, R. M., \& von Eye, A. (2000). Adolescent-parent discrepancies in perceptions of family functioning and early adolescent self-competence. International Journal of Behavioral Development, 24, 362-372. doi:10. 1080/01650250050118358.

Otterpohl, N., \& Wild, E. (2015). Cross-lagged relations among parenting, children's emotion regulation, and psychosocial adjustment in early adolescence. Journal of Clinical Child and Adolescent Psychology, 44, 93-108. doi:10.1080/15374416. 2013.862802.

Paus, T., Keshavan, M., \& Giedd, J. N. (2008). Why do many psychiatric disorders emerge during adolescence? Nature Reviews Neuroscience, 9, 947-957. doi:10.1038/nrn2513.

Pelton, J., \& Forehand, R. (2001). Discrepancy between mother and child perceptions of their relationship: I. Consequences for adolescents considered within the context of parental divorce. Journal of Family Violence, 16, 1-15. doi:10.1023/A: 1026527008239
Racz, S. J., \& McMahon, R. J. (2011). The relationship between parental knowledge and monitoring and child and adolescent conduct problems: A 10-year update. Clinical Child and Family Psychology Review, 14, 377-398. doi:10.1007/s10567-0110099-y.

Rescorla, L. A., Bochicchio, L., Achenbach, T. M., Ivanova, M. Y., Almqvist, F., Begovac, I., et al. (2014). Parent-teacher agreement on children's problems in 21 societies. Journal of Clinical Child and Adolescent Psychology, 43, 627-642. doi:10.1080/ 15374416.2014.900719.

Reynolds, E. K., MacPherson, L., Matusiewicz, A. K., Schreiber, W. M., \& Lejuez, C. W. (2011). Discrepancy between mother and child reports of parental knowledge and the relation to risk behavior engagement. Journal of Clinical Child and Adolescent Psychology, 40, 67-79. doi:10.1080/15374416.2011.533406.

Rote, W. M., \& Smetana, J. G. (this issue). Patterns and predictors of mother-adolescent discrepancies across family constructs. Journal of Youth and Adolescence. doi: 10.1007/s10964-016-0515-1.

Russell, J. D., Graham, R. A., Neill, E. L., \& Weems, C. F. (this issue). Agreement in youth-parent perceptions of parenting behaviors: A case for testing measurement invariance in reporter discrepancy research. Journal of Youth and Adolescence. doi: 10. 1007/s10964-016-0495-1.

Schwarz, N. (1999). Self-report: How the questions shape the answers. American Psychologist, 54, 93-105. doi:10.1037/ 0003-066X.54.2.93.

Shek, D.T. (2002). Chinese adolescents' perceptions of family functioning: Personal, school-related, and family correlates. Genetic, Social, and General Psychology Monographs, 128, 358-380. Retrieved from: http://search.proquest.com/openview/ ee8f79377ec2b5f8f2b5d43453f96986/1?pq-origsite=gscholar.

Shek, D. T. L. (2007). A longitudinal study of perceived differences in parental control and parent-child relational qualities in Chinese adolescents in Hong Kong. Journal of Adolescent Research, 22, 156-188. doi:10.1177/0743558406297509.

Skinner, O. D., \& McHale, S. M. (this issue). Parent-adolescent conflict in African American families. Journal of Youth and Adolescence. doi: 10.1007/s10964-016-0514-2.

Smetana, J. G. (1989). Adolescents' and parents' reasoning about actual family conflict. Child Development, 60, 1052-1067. doi: $10.2307 / 1130779$.

Smetana, J. G. (2008). 'It's 10 o'clock: Do you know where your children are?" Recent advances in understanding parental monitoring and adolescents' information management. Child Development Perspectives, 2, 19-25. doi:10.1111/j.1750-8606. 2008.00036.x.

Smetana, J. G., Campione-Barr, N., \& Metzger, A. (2006). Adolescent development in interpersonal and societal contexts. Annual Review of Psychology, 57, 255-284. doi:10.1146/annurev.psych. 57.102904.190124.

Steinberg, L. (1990). Autonomy, conflict and harmony in the family relationship. In S. S. Feldman \& G. R. Elliott (Eds.), At the threshold: The developing adolescent (pp. 255-276). Cambridge, MA: Harvard University Press.

Steinberg, L. (1991). Adolescent-parent relations. In R. M. Lerner, A. C. Petersen, \& J. Brooks-Gunn (Eds.), Encyclopedia of adolescence (pp. 724-728). New York: Garland.

Steinberg, L. (2005). Cognitive and affective development in adolescence. Trends in Cognitive Sciences, 9, 69-74. doi:10. 1016/j.tics.2004.12.005.

Tackett, J. L., Herzhoff, K., Reardon, K. W., Smack, A. J., \& Kushner, S. C. (2013). The relevance of informant discrepancies for the assessment of adolescent personality pathology. Clinical Psychology: Science and Practice, 20, 378-392. doi:10.1111/ cpsp.12048. 
Yaban, E. H., Say1l, M., \& Tepe, Y. K. (2014). Are discrepancies in perceptions of psychological control related to maladjustment? A study of adolescents and their parents in Turkey. International Journal of Behavioral Development, 36, 550-562. doi:10.1177/ 0165025414537880

Youngstrom, E. A., \& De Los Reyes, A. (2015). Commentary: Moving toward cost-effectiveness in using psychophysiological measures in clinical assessment: Validity, decision-making, and adding value. Journal of Clinical Child and Adolescent Psychology, 44, 352-361. doi:10.1080/15374416.2014.913252.

Yu, S., Clemens, R., Yang, H., Li, X., Stanton, B., Deveaux, L., et al. (2006). Youth and parental perceptions of parental monitoring and adolescent-parent communication, youth depression, and youth risk behaviors. Social Behavior and Personality, 34, 1297-1310. doi:10.2224/sbp.2006.34.10.1297.
Andres De Los Reyes is an Associate Professor in the Department of Psychology at the University of Maryland at College Park. He also is the Director of the Comprehensive Assessment and Intervention Program and Editor-Elect of the Journal of Clinical Child and Adolescent Psychology.

Christine McCauley Ohannessian is an Associate Professor of Pediatrics and Psychiatry at the University of Connecticut School of Medicine. She also is the Director of the Children's Center for Community Research at the Connecticut Children's Medical Center. 